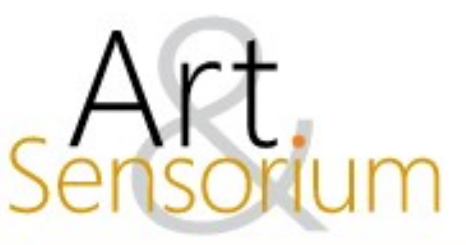

\title{
ARTE ANGOLANA CONTEMPORÂNEA: RUÍNA, ARQUIVO E O DEVER CRÍTICO DE MEMÓRIA NA POÉTICA DE DUAS GERAÇÕES DE ARTISTAS
}

\author{
DOI: https://doi.org/10.33871/23580437.2020.7.2.052-066
}

Adriana Cristina Aguiar Rodrigues ${ }^{1}$

\begin{abstract}
Resumo: Do século XV ao XX Angola esteve sob o poder dos portugueses. Entre 1961 e 1974 ocorreram lutas organizadas pela independência, conquistada em 1975. Após esse período, iniciaramse conflitos internos (oriundos de estruturas políticas e civis construídas pelo colonizador europeu) que só foram encerrados em 2002. Diante desse quadro histórico, cujas marcas ressoam na sociedade angolana, a nação ainda luta para reerguer seu espaço e preservar a memória. Em um país ainda deficitário em museus e em centros de arquivos, alguns artistas têm desempenhado um papel fundamental: por um lado, desarquivam o passado, revisitando-o criticamente; por outro, fazem de suas produções um arquivo (estético, ético e político) contra o esquecimento, construindo uma memória das lutas, das vítimas e dos rastros da violência colonial. Nesse contexto, este artigo, fruto de pesquisa de doutorado em andamento, procura, em primeiro momento, pensar como Angola ainda ressoa o que Michel Foucault denomina "heterotopias" e "heterocronias" coloniais. Após, são analisadas obras de António Ole e Kiluanji Kia Henda, artistas angolanos de duas diferentes gerações, que têm se debruçado sobre a temática de que aqui tratamos, isto é, as relações entre arte contemporânea angolana, arquivo e memória.
\end{abstract}

Palavras-chave: Arquivo; Memória; Artes visuais em Angola; António Ole; Kiluanji Kia Henda.

\section{CONTEMPORARY ANGOLAN ART: RUIN, ARCHIVE AND THE CRITICAL DUTY OF MEMORY IN THE POETICS OF TWO GENERATIONS OF ARTISTS}

Abstract: From the 15th to the 20th century Angola was under the power of the Portuguese. Between 1961 and 1974 there were struggles organized for independence, won in 1975. After that period, internal conflicts (arising from political and civil structures built by the European colonizer) began, which were only ended in 2002. Faced with this historical picture, whose marks resonate in Angolan society, the nation still struggles to rebuild its space and preserve its memory. In a country still lacking in museums and archival centers, some artists have played a fundamental role: on the one hand, they unarchive the past, critically revisiting it; on the other, they make their productions an archive (aesthetic, ethical and political) against forgetfulness, building a memory of the struggles, victims and traces of colonial violence. In this context, this article, the result of ongoing doctoral research, seeks, at first, to think how Angola still resonates what Michel Foucault calls "colonial heterotopies" and "heterocronies". Afterwards, works by António Ole and Kiluanji Kia Henda, Angolan artists

\footnotetext{
${ }^{1}$ Professora Assistente de Literatura na Universidade Federal do Amazonas (UFAM), com doutorado em andamento em Teoria e História Literária pela Universidade Estadual de Campinas (UNICAMP), com foco nas artes visuais e na literatura angolana produzida entre 1990 e 2020, pela qual a autora é contemplada com bolsa de pesquisa financiada pela CAPES em parceria com a Fundação de Amparo à Pesquisa do Amazonas (FAPEAM). Orcid: http://orcid.org/00000002-2192-9981. E-mail: adrianaguiarodrigues@gmail.com.
} 
from two different generations, who have been working on the theme we are dealing with here, that is, the relations between Angolan contemporary art, archive and memory, are analyzed.

Keywords: Archive; Memory; Visual arts in Angola; António Ole; Kiluanji Kia Henda.

\section{EL ARTE ANGOLANO CONTEMPORÁNEO: RUINA, ARCHIVO Y EL DEBER CRÍTICO DE LA MEMORIA EN LA POÉTICA DE DOS GENERACIONES DE ARTISTAS}

Resumen: Desde el siglo XV al XX, Angola estuvo bajo el poder de los portugueses. Entre 1961 y 1974 se organizaron luchas por la independencia, ganadas en 1975. Después de ese período, comenzaron los conflictos internos (surgidos de las estructuras políticas y civiles construidas por el colonizador europeo), que no terminaron hasta 2002. Frente a este cuadro histórico, cuyas huellas resuenan en la sociedad angoleña, la nación todavía lucha por reconstruir su espacio y preservar su memoria. En un país aún carente de museos y centros de archivo, algunos artistas han jugado un papel fundamental: por un lado, desarchivan el pasado, revisándolo críticamente; por otro, hacen de sus producciones un archivo (estético, ético y político) contra el olvido, construyendo una memoria de luchas, víctimas y huellas de la violencia colonial. En este contexto, este artículo, resultado de una investigación doctoral en curso, busca, en un primer momento, pensar cómo Angola aún resuena lo que Michel Foucault denomina "heterotopías coloniales" y "heterocronías". Posteriormente, se analizan obras de António Ole y Kiluanji Kia Henda, artistas angoleños de dos generaciones diferentes, que han estado trabajando en el tema que estamos tratando aquí, es decir, las relaciones entre el arte contemporáneo angoleño, el archivo y la memoria.

Palabras clave: Archivo; Memoria; Artes visuales en Angola; António Ole; Kiluanji Kia Henda.

No documentário "Cartas para Angola", dirigido por Coraci Ruiz e Júlio Matos, brasileiros, portugueses e angolanos têm suas histórias (entre)cruzadas por cartas e narrativas sobre migração e pertencimento. $\mathrm{O}$ apelo memorialístico, na produção, chama atenção, em especial, para a fala dos angolanos: a Guerra de Independência de Angola (1961-1974) e a Guerra Civil Angolana (19752002), eventos traumáticos para a nação, apresentam-se nos discursos, carregados pelos verbos "perder", "ver", "ouvir", "lembrar" e pelo substantivo "guerra". Fruto também da relação entre Brasil e Angola, a Rede Bandeirantes exibiu, em junho de 2013, o programa "Luanda - o mundo segundo os brasileiros". Durante a reportagem, um passeio, conduzido por brasileiros residentes na capital de Angola, revela mais de trinta carcaças de navios na praia de Santiago, além de tanques e outros blindados abandonados pelas províncias. São restos dos anos de guerra que parecem compor uma coleção de objetos de um museu a céu aberto (aí também incluídos os terrenos minados) que reside, ainda de forma vivaz, na rotina e na memória dos angolanos. Os artefatos - que hoje compõem a paisagem de Angola, e, de algum modo, as falas e os corpos dos sujeitos que habitam as cidades revelam as marcas da violência imperialista, as quais ainda se apresentam de forma material (como exibido no programa da Bandeirantes) e imaterial (como revela o discurso memorialístico dos atores de "Cartas para Angola").

Levando em consideração esta realidade suscitada pelas imagens e pelos discursos presentes nestas duas produções visuais, proponho-me, neste artigo, refletir sobre as relações entre arquivo, arte e memória em Angola. Para tanto, no primeiro momento, esses objetos decaídos (ASSMANN, 2011) serão pensados a partir da definição de "heterotopia" ou "contraespaços", dada por Michel Foucault (2013). Posteriormente, tomarei como objeto de análise projetos desenvolvidos por dois artistas angolanos, de duas diferentes gerações, António Ole e Kiluanji Kia Henda, para refletir acerca dos

R. Inter. Interdisc. Art\&Sensorium, Curitiba, v.7, n.2, p. 052 - 066 Jul.- Dez. 2020 
modos como cada um deles manipula linguagens para, ao romper com a formalidade do arquivo clássico (DERRIDA, 2001), desarquivar o não arquivado (em sentido clássico), procedendo, assim, via arte, a uma revisão crítica do passado-presente, colaborando para a constituição de uma memória cultural coletiva.

\section{Heterotopias de objetos sem museus: ou sobre o não arquivado}

Conforme Michel Foucault, "em geral, a heterotopia tem como regra justapor em um lugar real vários espaços que, normalmente, seriam ou deveriam ser incompatíveis" (2013, p. 24). Além disso, elas são frequentemente ligadas a recortes singulares de tempo, isto é, "heterocronias". É o que se nota no caso de Angola, em que um amontoado de partes do passado expressa um acúmulo temporal: em um tempo de paz, os moradores convivem com resquícios da guerra, com marcas de projéteis e explosivos deixados nos corpos e nas paredes de prédios e da memória. Em outras palavras, acumulam-se tempo de guerra e tempo de paz; tempo de colonialismo e tempo de independência, que se manifestam em heterotopias, isto é, espaços que reúnem e ao mesmo tempo separam o que está em uso e o que foi descartado; o ativo e o inativo. Muitas vezes, tais categorias se mesclam, como se o passado estivesse ainda em funcionamento. Vejam-se, por exemplo, as diversas ruínas e habitações ainda perfuradas por vestígios da guerra, mas ocupadas por moradores, alguns deles sobreviventes.

Nação jovem, com 44 anos, e tendo vivido quase um genocídio cultural durante os anos de colonização, Angola dispõe de poucas "heterotopias do tempo" (FOUCAULT, 2013) - organizadas e sistematizadas -, como museus, bibliotecas, centros de arquivo e instituições voltadas para a preservação do patrimônio público. Conforme Sitak et al (2018, p. 281), o país conta, atualmente, com dezesseis museus públicos (dos quais oito estão localizados na capital do país), a saber: Museu de Geologia (1929); Museu Etnográfico do Dundo (1936); Museu de Etnografia do Lobito (1930/1940); Museu Regional de Cabinda (1940); Museu do Planalto Central Huambo (1948); Museu Regional da Huíla (1953); Museu de História Natural (1976); Museu Nacional de Antropologia (1976); Museu Nacional da Escravatura (1977); Museu Regional dos Reis do Congo (1978); Museu de Arqueologia de Benguela (1978); Museu Nacional de História Militar (1978); Museu da Pesca do Namibe; Museu da Força Aérea Nacional (2012); Museu da Moeda (2016); e o Museu do Café. Vale destacar que o Museu da História Militar se constitui como um dos poucos espaços dedicados à memória do colonialismo e das guerras - seja através da exposição de artefatos, seja através de um conjunto de discursos (nacionalistas) proferidos por autoridades e, posteriormente, esculpidos em placas de madeira e de ferro ou impressos e expostos ao longo da parede do corredor central do prédio. Em uma dessas placas, o visitante pode ler o seguinte texto assinado pelo comandante Iko Carreira: "Para que oficiais, sargentos e soldados das FLAPA, as gerações vindouras possam instruir-se sobre [...] os sacrifícios que ao longo dos séculos o nosso povo ofereceu para poder ser livre, foi criado este museu". E mais adiante, outro texto, de autoria de Carlos Rocha Dilolwa, expõe as rasuras que se fazem neste espaço e as diferentes temporalidades que ele abriga: “[...] tem caráter simbólico o facto de uma fortaleza colonial, que foi reduto do exército colonial e que ultimamente abrigava o EstadoMaior do exército colonial-fascista, se ter transformado no Museu das Forças Armadas do Povo"2.

Outro importante espaço de documentação histórica, o Arquivo Nacional de Angola, alocado em prédio em condições precárias, na cidade de Luanda, e cuja documentação inclui entre 13 e 15 mil códices, o núcleo do governo de Benguela, a secretaria geral do governo, o governo geral de Angola, a imprensa, a alfândega, os tribunais e correspondências, dos séculos XVIII ao XX, ainda carece de funcionários em número suficiente para organizar, catalogar, preservar e disponibilizar os arquivos, como afirma a atual diretora geral, Alexandra Aparício, em entrevista concedida à Iracema Dulley:

\footnotetext{
${ }^{2}$ As informações foram retiradas de registros fotográficos feitos pela autora quando de sua visita ao museu, em 2019.
} 
"Temos mais de cinco mil caixas com documentos e milhares de maços que ainda nem sequer conseguimos organizar, pois a equipe é pequena" (2017, p. 233).

Diante desse cenário, as manifestações históricas e memorialistas acabam, muitas vezes, sendo acomodadas em produções estéticas, seja na fotografia, nas artes plásticas ou na literatura, como destaca a professora Tania Macedo: "São anos de guerra que causaram uma exaustão do país e sua gente, trazendo consigo uma cultura da perda que, sem dúvida, esgarçou o tecido social" (2008, p. 206-207). Essa "cultura da perda", como denominada por Macedo, forja uma forma estética que se assenta no limite entre ficção e real, imaginário e testemunho. Uma guinada subjetiva da memória, como sinaliza Beatriz Sarlo (2007), que coloca o pesquisador das artes diante de uma nova forma de se relacionar com o real e com eventos-limites.

É a partir de 1948 que ações desenvolvidas por angolanos, como o Movimento dos Novos Intelectuais de Angola (MNIA) e os poetas da revista Mensagem, ao lançarem o lema "Vamos descobrir Angola", colocam intelectuais e artistas locais diante do desafio de criar nas artes a imagem da nação que, naquela época, desejava-se alcançar: era preciso buscar e valorizar o passado, a terra angolana e suas gentes antes da contaminação imposta pela sociedade colonial (FONSECA, 2008, p. 32). No número triplo (2/3/4) da revista Mensagem, são publicados, por exemplo, "Dois poemas à terra" e "Serão de menino", de Viriato da Cruz, e o conto "Náusea", de Agostinho Neto, "sem dúvida uma importante referência literária ao projeto de angolanidade que se firmava na denúncia à opressão colonialista e à consequente descaracterização do espaço angolano" (FONSECA, 2008, p. 34). É ainda na segunda metade do século XX, como revela a pesquisa de Tania Macedo (2008, p. 113), que Luanda e os musseques passam a se configurar como espaços de luta e de resistência frente ao colonialismo. É assim que essas moradias da marginalização colonial surgem na música, na literatura e nas artes plásticas como imagem de resistência e da identidade nacional. Juntamente com manifestações literárias acerca do período de guerra, situam-se instalações, fotografias e performances de artistas que se vinculam à memória do passado colonial e de guerras. É o caso das obras de dois fotógrafos brasileiros: África (2007), de Sebastião Salgado - em que se expõe uma série de fotografias cuja temática são as marcas da guerra impressas em corpos de crianças, jovens e de senhoras (Figura 1); e Duas ou três coisas que eu vi em Angola (2000), de Sérgio Guerra - que representa, dentre outros, espaços-imagens de moradores angolanos habitando ruínas de prédios marcados por guerras (Figura 2).

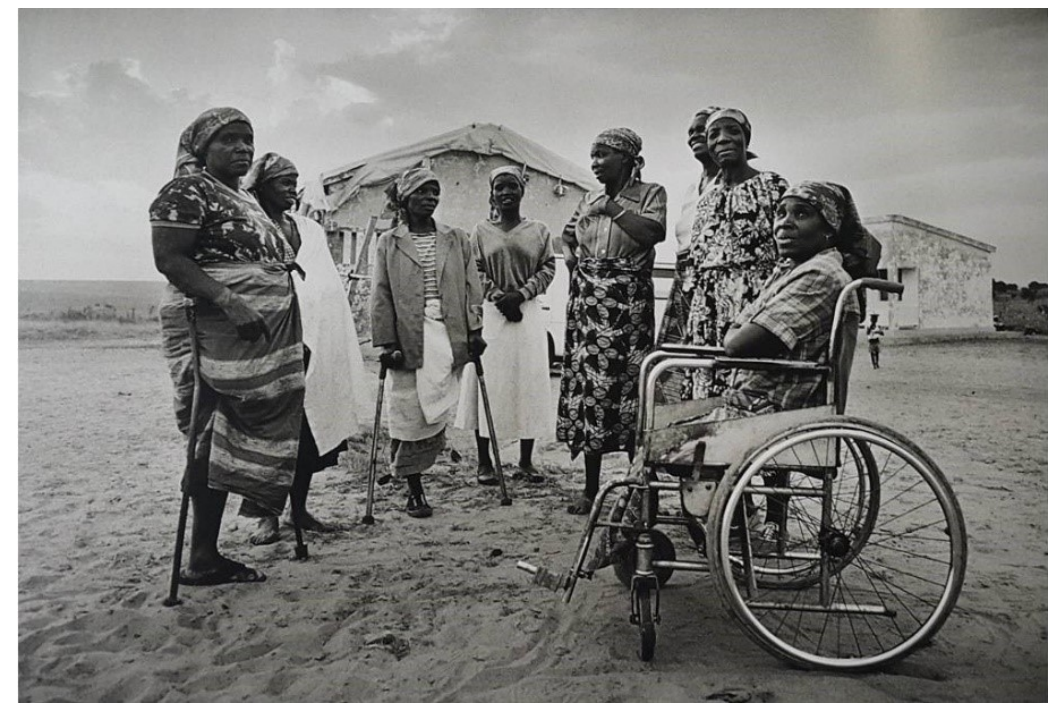

Figura 1 - Sebastião Salgado. "Vítimas de minas terrestres no centro ortopédico da Cruz Vermelha Internacional, em Bomba Alta, na cidade de Huambo, Angola, 1997". Impressão fotográfica. Fonte: Salgado, 2007. 


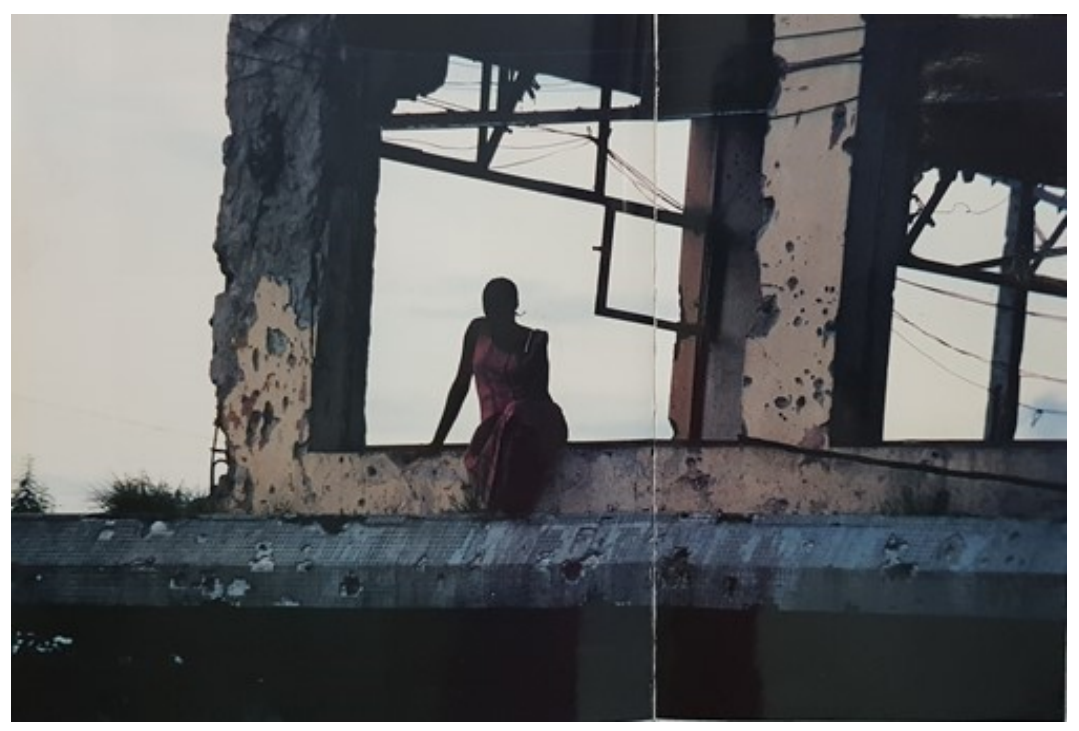

Figura 2 - Sérgio Guerra. "Kuito-Bié”. Impressão fotográfica. Sem data. Fonte: Guerra, 2000.

Dialogando com o que aponta Tania Macedo (2008), especificamente no que toca à reflexão em torno da história do país e da sociedade que moldaram o espaço da cidade de Luanda, a pesquisadora alemã Nadine Siegert (2018), ao analisar as relações entre memória, trauma e arte angolana, destaca as marcas das guerras não só nos corpos das vítimas de minas, como também no corpo da cidade, com sua infraestrutura abalada, sobretudo nos bairros informais. Para ela, um dos caminhos para trazer à vista as ruínas do passado colonial manifestadas no período da independência é pela dimensão espacial, pela forma da paisagem e dos lugares, uma vez que esses podem atuar como portadores de memória que se referem a um passado (in)visível. Em que pese o silenciamento estético em relação ao colonialismo e ao trauma da guerra, na década de 1990, o período pós-guerra, como aponta Siegert, é marcado nas artes pelo debate em torno desse legado. Dentre as produções de artistas angolanos que se inserem nesse contexto de quebra do silenciamento estético em relação ao colonialismo, chamam-nos a atenção as produções de dois artistas: António Ole - cineasta, artista plástico e fotógrafo que faz releituras e criações artísticas a partir de espaços de Angola; e Kiluanji Kia Henda, artista visual da nova geração angolana, que se dedica à relação entre espaço, cidade, período précolonial e colonização. É partindo dessa realidade, isto é, de uma memória desdobrada dos episódios históricos transcorridos na Angola colonial e pós-independência, que busco analisar, a seguir, o modo como esses dois artistas lidam com arquivos, apontando algumas de suas obras como formas de lidar com o passado, cujas ruínas reverberam no espaço angolano do presente.

\section{Imagens (des)arquivadas: da arte como dever crítico de memória}

Começo esta seção com duas imagens oriundas de pesquisa artística multidisciplinar em torno das arquiteturas e vivências dos musseques da cidade de Luanda, iniciada por António Ole, na década de 1970. Na primeira fotografia (Figura 3), veem-se paredes e cacos de tijolos no chão. Apesar de a estrutura do que parece ser uma casa conter recortes para porta e janela, a relação entre o espaço de dentro e o de fora se insinua bloqueada por passagens que (do ângulo em que se encontra o fotógrafo) esbarram em outras paredes duras de cimento ou em tijolos que lacram a janela, deixando apenas uma fresta escura na parte superior. Não há sinal de habitantes e o ambiente sugere abandono e ruínas. Na segunda fotografia (Figura 4), em preto e branco, veem-se habitações que parecem avançar umas sobre as outras e cujas estruturas são armadas com blocos de alumínio, tecido, plástico e madeira. Nas coberturas, entre objetos não identificáveis, nota-se um cesto; no canto esquerdo da mureta com encanamento à mostra, observa-se uma vara fina escorando a parede onde alguns rabiscos e palavras R. Inter. Interdisc. Art\&Sensorium, Curitiba, v.7, n.2, p. 052 - 066 Jul.- Dez. 2020 
(como "rainha", "poder", "police") estão registrados. À direita, uma mulher, cujo rosto não se consegue ver, está curvada sobre uma bacia, próxima a outras três.

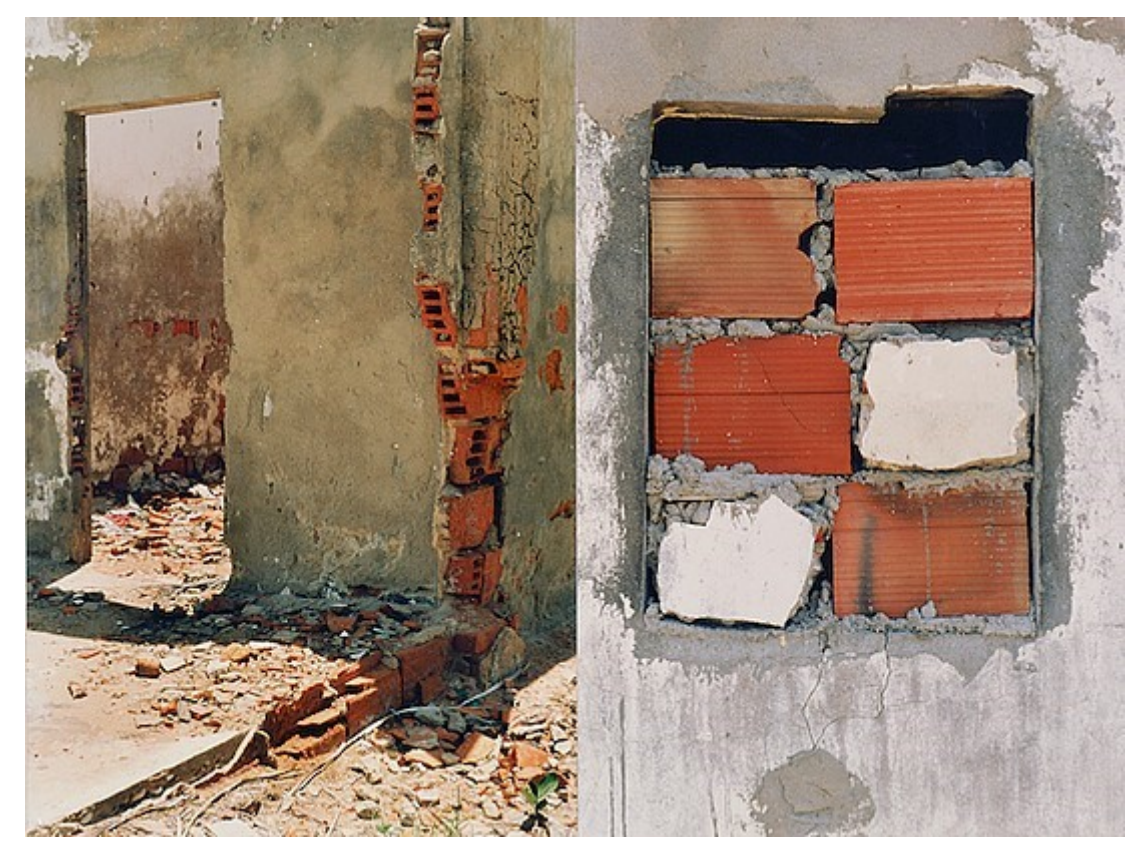

Figura 3 - António Ole. Sem título (I). Impressão fotográfica. 90 x $120 \mathrm{~cm} .1998^{3}$. Fonte: António Ole.

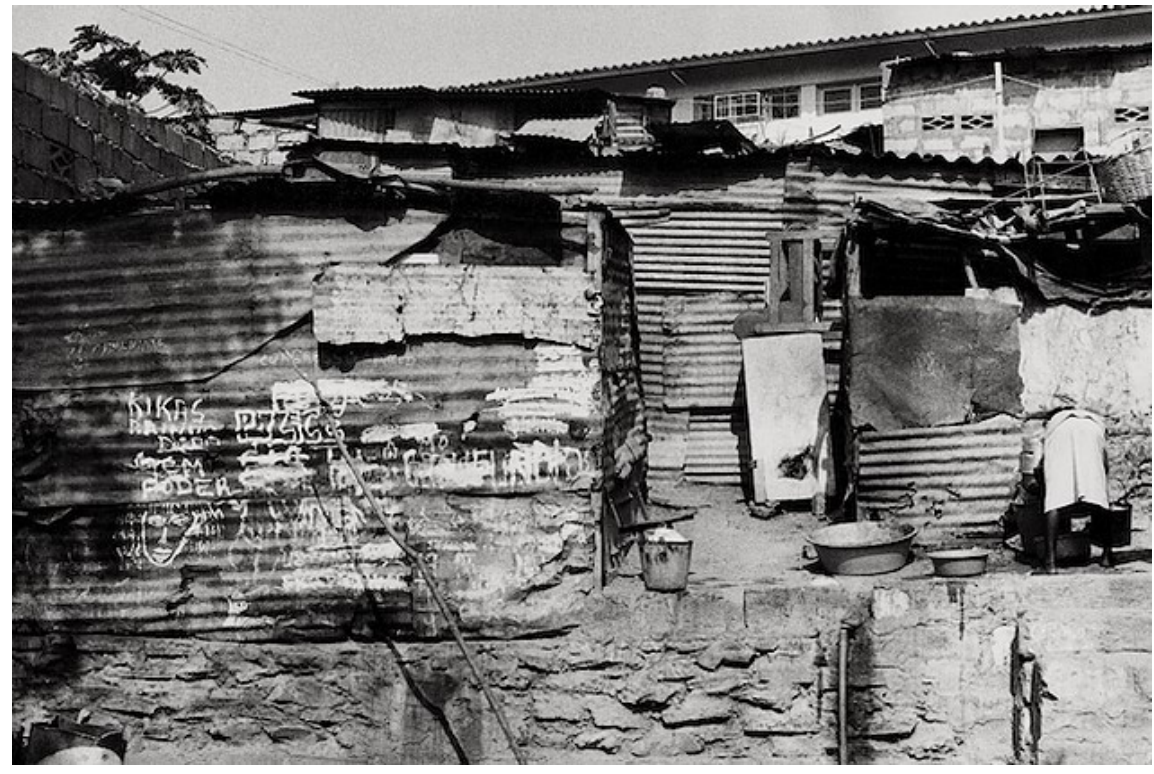

Figura 4 - António Ole. Sem título. Impressão fotográfica. Sem data. Fonte: António Ole.

Em primeiro olhar, as duas imagens expõem o fascínio do artista pela arquitetura das construções dos musseques e as fraturas atuais de uma das capitais mais caras do mundo e de um país onde $90 \%$ dos que vivem na área urbana residem em habitações em condições não apropriadas, conforme mostra o Relatório de Inquérito Integrado sobre o Bem-Estar da População - IBEP - (2011). Por outro lado,

\footnotetext{
${ }^{3}$ As imagens de trabalhos de António Ole foram retiradas do site do artista: $<$ https://www.antonioole.com>.
} 
Teresa Matos Pereira (2013, p. 182), ao analisar o conjunto de fragmentos da paisagem urbana de Luanda que se apresenta nas fotografias de Ole, afirma que esse não poderá ser encarado apenas na sua dimensão puramente visual, mas numa reflexão mais ampla em torno da história do país e da sociedade que inevitavelmente foram moldando o espaço da cidade. A dimensão visual da imagem que Ole entrega ao espectador é, portanto, conjugada com aspectos mais profundos, como a invisibilidade das camadas mais pobres da população, metaforizada, nas fotografias, pela ausência de pessoas, na primeira, e pela mulher, cuja face não se pode ver, na segunda.

Alfons Hug (1998), ao comentar o percurso de Ole, destaca que o artista - como outros do continente africano oriundos de países que conquistaram a independência na segunda metade do século XX atravessou diferentes fases no decorrer de sua carreira: uma mais otimista, no início da década de 80; e outra mais realista, profundamente impactada pelas guerras e pelas catástrofes que se sucederam nas primeiras décadas do período pós-independência. É a partir dos condicionamentos históricos que Ole lança mão de novos recursos estéticos "para traduzir adequadamente a complexidade da nova realidade africana" (HUG, 1998, p. 101); e é nas ruas que o artista plástico vai coletar materiais para a nova fase artística:

O declínio das cidades, devastadas pelo tumulto da guerra e as vertiginosas crises econômicas forneceram os achados com que António Ole e os seus pares transformaram a realidade africana em arte. Pedaços de lixo deitados fora, plástico sem valor, desperdícios de madeira e de ferro ferrugento vieram substituir os tradicionais recursos pictóricos da tela e da madeira esculpida. [...] António Ole gosta igualmente de convocar reminiscências históricas de fotografias, usando nomeadamente fotografias achadas do porto de Luanda para reconstruir o período colonial português. No entanto, as preocupações centrais na obra do artista são a pobreza e o empobrecimento, a guerra, destruição e a desintegração das estruturas (HUG, 1998, p. 102).

Por sua vez, Maria José, ex-presidente do Instituto Camões, ao se referir à obra de António Ole, no catálogo António Ole e Contiguidades (2003, p. 3), afirma que o artista absorve e conjuga as referências temáticas e culturais mais díspares, "da mitologia arcaica ao urbano espúrio e violento" (2003, p. 4). Tanto Hugs quanto Maria José destacam o fazer estético de Ole entremeado por aspectos do real, pela presença física de restos de Angola. Restos, todavia, ressignificados, reelaborados em signos outros, para além do real. Ao construir, com fragmentos de madeira, ferro, plástico e outros objetos recolhidos pela cidade, Ole "coloca a luta diária pela sobrevivência no centro de sua obra" (HUG, 1998, p. 102), assemelhando-se à figura do trapeiro baudelairiano.

Esse mote do que é destruição de um espaço anterior e o que são restos e sobras de construção de um espaço posterior se revela, para além das fotografias, em outros trabalhos do artista. Um exemplo é a instalação "Margem da Zona Limite", cuja montagem inicial data de 1994; e, de 1995, a exposição na Primeira Bienal de Joanesburgo. Nela, o artista (re)contextualiza e acumula diversos objetos encontrados (objet trouvé) em viagens prospectivas que fez pelo país e pelos musseques de Luanda. Uma das partes dessa obra constitui-se da estrutura (feita de ferro) de uma embarcação, seccionada em duas partes (Figura 5): de um lado, uma pilha de tijolos de barro e um corvo embalsamado, com asas e bico abertos, mira a imagem de um mar em um televisor; de outro, uma pilha de papéis, pastas de arquivos e mais um corvo com asas fechadas, também a mirar a imagem do mar em outro televisor. 


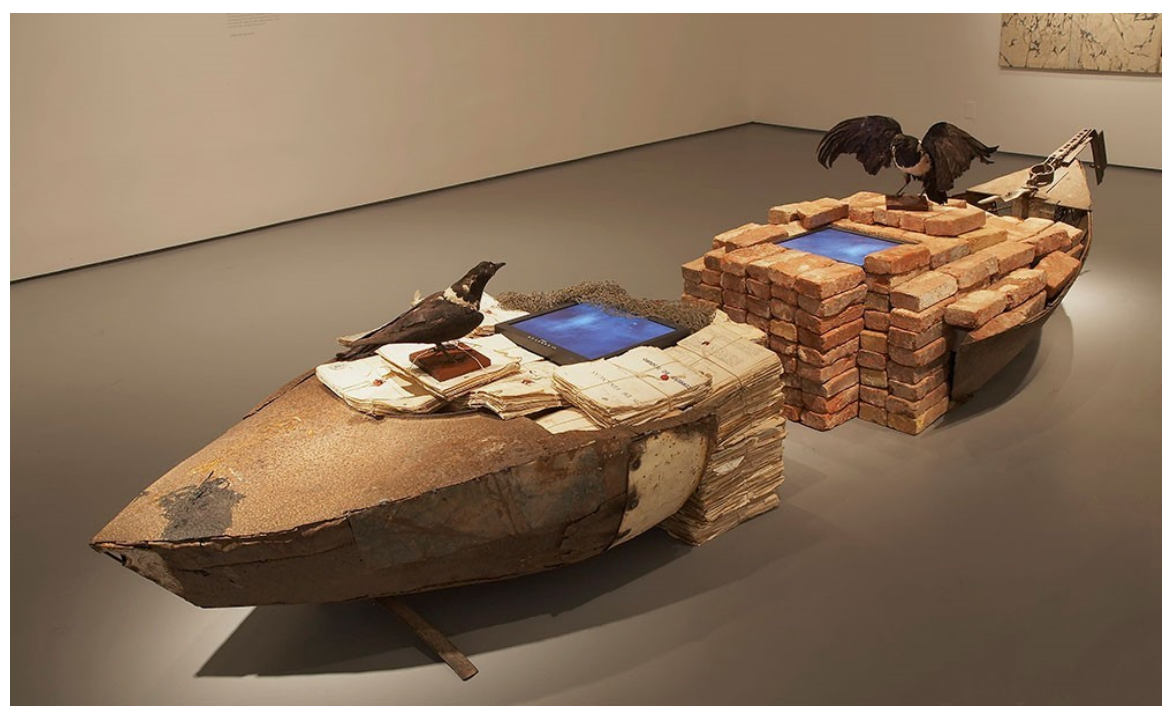

Figura 5 - António Ole. Fragmento da instalação "Margem da Zona Limite". Joanesburgo (1995). Fonte: António Ole.

A presença das aves suscita a imagem da morte, visto que os corvos se alimentam de carne em decomposição, mas está relacionada também à figura do mensageiro ${ }^{4}$. Quanto a esse aspecto, a narrativa bíblica oferece exemplos de interesse para a análise dos elementos que compõem a embarcação de "Margem da Zona Limite". A ave aparece no livro de Gênesis (8:6-7), em episódio sobre o dilúvio: "Ao cabo de quarenta dias, abriu Noé a janela que fizera na arca e soltou um corvo, o qual, tendo saído, ia e voltava, até que se secaram as águas sobre a terra”. Em outro livro do Antigo Testamento, corvos alimentam o profeta Elias quando esse é perseguido pelo rei Acabe e a rainha Jezabel e tem de migrar de sua terra e enfrentar dias de seca e fome: "Retira-te daqui, vai para o lado oriental e esconde-te junto à torrente de Querite, fronteira do Jordão. Beberás da torrente; e ordenei aos corvos que ali mesmo te sustentem" (I Reis. 17.3-4). O retorno do corvo à arca, onde Noé guarda sua coleção de espécies naturais que vão povoar um novo mundo, oferece a ele a mensagem de que ainda não há terra para pousar nem como se alimentar. As duas narrativas, a de Noé e a de Elias, associam corvos, saída da terra de morada para outra terra desconhecida e mar.

Ao reunir em sua "arca" aves, papéis de arquivo, tijolos de barro (terra) e a imagem do mar, Ole nos remete, por um lado, à figura do arconte, aquele que vela ou guarda uma mensagem (da violência colonial, da guerra, das vítimas, da terra invadida) ainda por ser comunicada, interpretada e/ou (des)arquivada - daí o corvo com asas fechadas, como um guardião. Por outro lado, a imagem do corvo de asas abertas sobre os tijolos de terra indicia uma postura de que se está prestes a alçar voo, distanciar-se da terra/morada em direção ao mar, em busca de outras terras. A instalação, no contexto histórico, remete à viagem (interrompida em função da ruptura da embarcação) e aos deslocamentos, tanto em relação à Europa e à África quanto em relação aos migrantes e refugiados da guerra civil que naquela altura se fazia no interior do país, enquanto Luanda se constituía como uma ilha de desterro.

Em outra parte da mesma instalação, Ole ergue, com madeira, chapa ondulada metálica, alumínio e vidro (Figura 6) - os mesmos objetos presentes nas construções dos musseques fotografadas por ele - uma parede, espécie de abrigo improvisado às vítimas, aos que são obrigados a deixar sua morada.

\footnotetext{
${ }^{4} \mathrm{Na}$ mitologia grega, o corvo é associado ao deus Apolo e desempenha o papel de mensageiro dos deuses, pois possui função profética. Na mitologia nórdica, o corvo é associado a Odin, deus da sabedoria, da poesia, da magia, da guerra e da morte.
} 


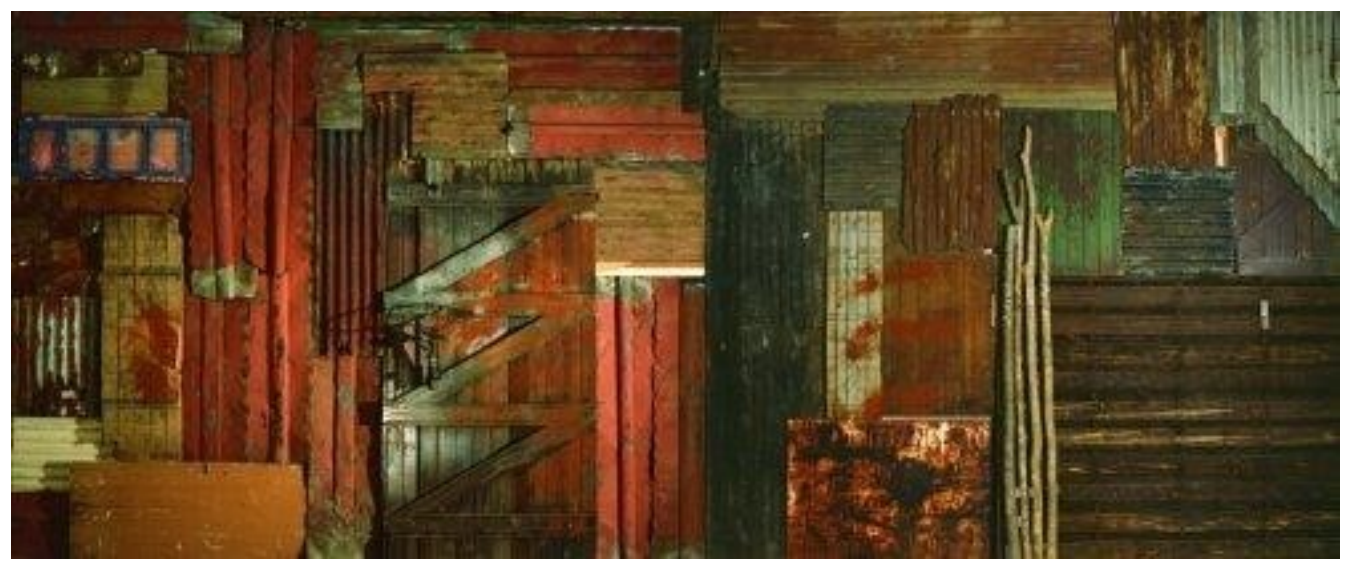

Figura 6 - António Ole. Fragmento da instalação "Margem da Zona Limite". Joanesburgo (1995). 400 x 1200 cm. Fonte: António Ole.

Construindo arte com os restos das diversas camadas da cidade de Luanda e do país, esse chiffonnier recolhe "tudo aquilo que a cidade grande rejeitou, tudo o que ela perdeu, tudo o que ela desdenhou, tudo o que destruiu: tudo isso ele coleta e organiza. Ele administra os arquivos do excesso, a sala de quinquilharias do lixo" (BAUDELAIRE apud ASSMANN, 2011, p. 413). Todavia, esse artista trapeiro coleta não apenas o lixo do dia que passou, mas também as formas de resistência desenvolvidas pelos sobreviventes de Angola.

Se António Ole, figura tutelar de uma geração de novos artistas angolanos, - nascido em 1951, atravessou a luta contra o colonialismo, viu o país entrar e sair da guerra civil, produziu desde 1967 - debruça-se, a partir da paisagem e da arquitetura, sobre o passado de Angola, isto é, o da colonização, da guerra civil e dos restos que esses eventos ainda operam na cidade de Luanda; Kiluanji Kia Henda - nascido em 1979, de uma mãe que tinha 21 anos de idade quando a guerra pela independência começou e 62 anos quando a guerra civil terminou - é da nova geração de artistas que nasceu numa Angola jovem e independente, mas assolada pela guerra civil; e cresceu numa Luanda que se modernizava e se tornava cosmopolita, mas ao mesmo tempo não alcançava o projeto de uma nação utópica, construído a partir de 1950, quando Ole era uma criança.

Como o autor de "Margem da Zona Limite", é também para as estruturas arquitetônicas, para as edificações, os espaços e as guerras que Kiluanji se volta em parte de seu trabalho artístico. Mas vai além, alcançando um passado anterior, que abarca do imaginário pré-colonial ${ }^{5}$ às ações do colonizador e o período de independência. Esses temas são tomados por esse jovem artista em uma perspectiva crítica de revisão de diversos tipos de arquivos do passado em diálogo com o presente. Em entrevista concedida à Anabela Mota Ribeiro (2011), ele afirma:

A instabilidade que se viveu, a falta de documentação, de livros, espoletou o meu interesse em recuperar resquícios dessa fase. Houve quase um genocídio cultural em Angola nos anos 80 causado pela situação de guerra. [...] Ainda é difícil fazer um quadro do que foi o país nestes 35 anos. Um balanço. Faltam depoimentos, faltam imagens. O meu trabalho lida com isso. Tentar recuperar o que está presente dessa história passada.

\footnotetext{
${ }^{5}$ Exemplo de trabalho com essa temática é a série de fotografias “In The Days of a Dark Safari”. Realizada em 2017, em cenário montado no Museu Nacional de História Natural, a série problematiza o imaginário acerca de um passado précolonial paradisíaco e imaculado (na visão do africano) e infernal (na visão do colonizador). Ao mesmo tempo, confrontase esse passado com o presente, marcado pela corrupção e pela exploração irracional dos recursos naturais.
}

R. Inter. Interdisc. Art\&Sensorium, Curitiba, v.7, n.2, p. 052 - 066 Jul.- Dez. 2020 
Em 2009, Kia Henda recupera, através de fotografias, vestígios dessa "história passada" na Província de Huambo (a 600 quilômetros de Luanda), onde ocorreu um dos mais sangrentos episódios da guerra civil. Ocorrido em 1993, o conflito armado que ficou conhecido como "Guerra dos 55 dias", teve início após membros da União Nacional para a Libertação Total de Angola (UNITA) rejeitarem a vitória do Movimento Popular Pela Libertação de Angola (MPLA) nas eleições de 1992. Depois de mais de cinco dezenas de dias de confronto, a cidade ficou destruída, restando apenas escombros e diversas vítimas. Henda expõe esse passado em diálogo com o presente, em que paredes em concreto operam como páginas amareladas, ou como arquivos de bombas e balas, cujos estilhaços ainda impregnam as paredes escarificadas.

O título "Big Bang", dado a uma das fotografias (Figura 7), inscreve-se no campo semântico de uma cosmogonia, mas, de forma paradoxal, soa também como onomatopeia de extermínio e finitude. Ideia reforçada pelo enquadramento do buraco no centro da imagem e das várias perfurações ao redor, como uma onda explosiva a percorrer a parede. Em "Balas e satélites" (Figura 8), observa-se uma parede com sinais que indicam a presença humana, a julgar pelas antenas instaladas, que, por sua vez, suscitam a imagem de canhões apontados para o alto. Junto com as antenas, as marcas de bala e as grades sobre grades, o quadro sugere clausura, violência e transição de um passado com chuvas de balas para um presente em que a tecnologia se inscreve sobre rastros de projéteis. Corpos ausentes de vítimas assassinadas dão lugar a novos sujeitos, alguns deles sobreviventes, que convivem com e entre as ruínas.

Em outros projetos, o artista se volta para o tema da transição de poder em Luanda. Nos anos que se seguiram à independência, monumentos públicos em homenagem a colonizadores, dentre eles Vasco da Gama, Camões, Dom Afonso Henriques, Diogo Cão e Paulo Dias de Novais, foram retirados de seus pedestais e transferidos para a antiga Fortaleza de São Miguel, atual Museu Nacional de História Militar, reinaugurado em abril de 2013. Para o mesmo local foi levada a escultura da Rainha Njinga, erigida no período pós-independência e que havia sido removida temporariamente do Largo do Kinaxixi (em reforma). Henda, como um arconte-trapeiro, apropria-se desse processo de mutação do espaço urbano (em parte muito criticado pela população que defendia a manutenção das esculturas nos largos e em outros locais onde se encontravam) para compor a série "Homem Novo" (20102012), na qual, passados dez anos do final da guerra colonial, volta-se à questão do desmonte das estruturas coloniais e da formação da nova identidade angolana, cantada no hino nacional do país independente: "honramos o passado e a nossa história, construindo no trabalho o homem novo".

Em "Balumuka - Ambush" (2010), que compõe parte dos trabalhos de "Homem Novo" (Figura 9), Henda se aproveita de um cenário composto pela deposição desses vários objetos. As fotografias de placas desmontadas, bustos depositados no chão, estátuas desentronizadas, projéteis de canhões e viaturas - feitas na altura em que se realizava o inventário museográfico - formam um cenário bélico que parece estar abandonado e encarcerado entre placas de alumínio. O título da série de doze fotografias já indicia o sentido da narrativa criada pelas imagens: "balumuka" é um vocábulo da língua kimbundo que significa "erguer-se, levantar-se"; ao justapor o termo a um vocábulo da língua inglesa (ambush) que pode ser traduzido como "cilada, emboscada", o artista insere seu trabalho numa revisão pós-colonial do passado, em que o presente atua ainda como tempo de erguer-se da emboscada colonial. 


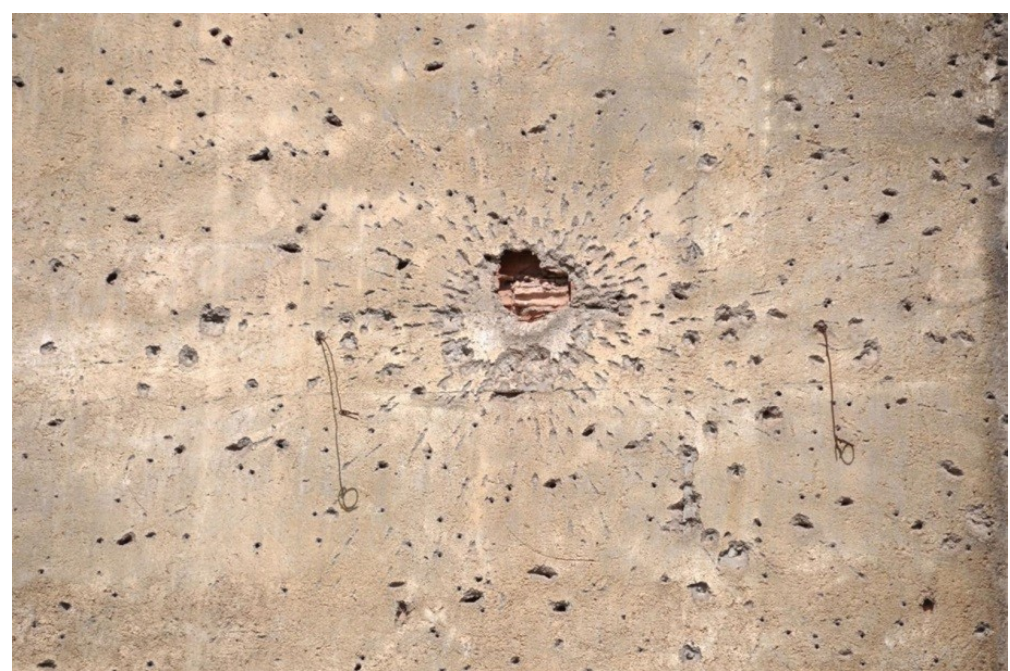

Figura 7 - Kiluanji Kia Henda. "Big Bang", Huambo. 2009. 86,5 x $130 \mathrm{~cm}$ x $130 \mathrm{~cm}$. Fonte: Johannes Hossfeld, 2016.

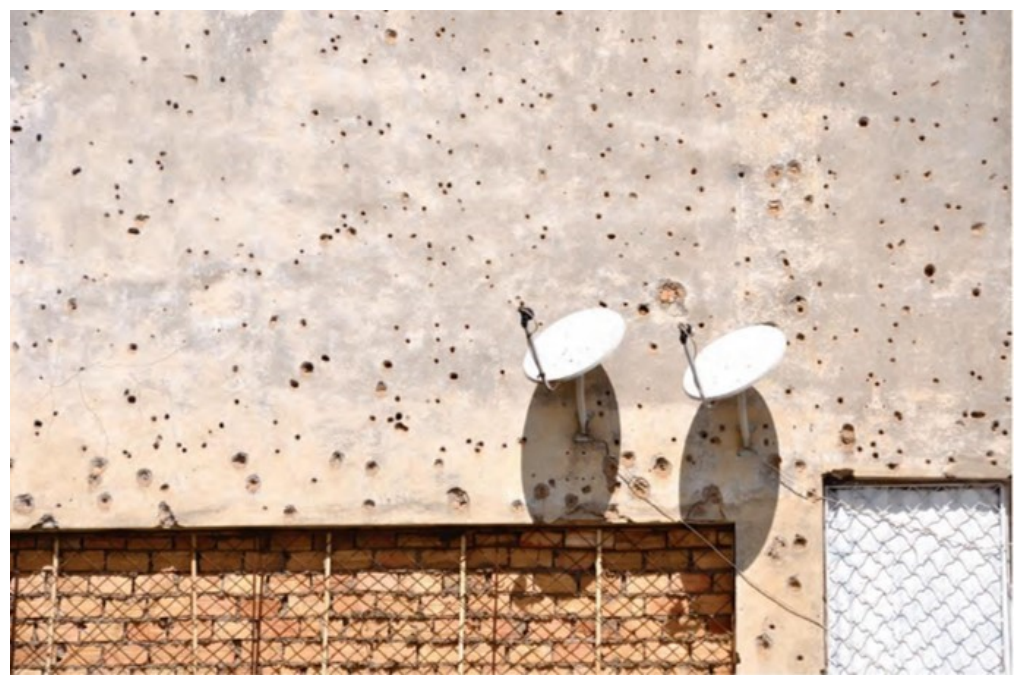

Figura 8 - Kiluanji Kia Henda. "Balas e Satélites". 2009. 86,5 x $130 \mathrm{~cm}$. Fonte: Johannes Hossfeld, 2016.

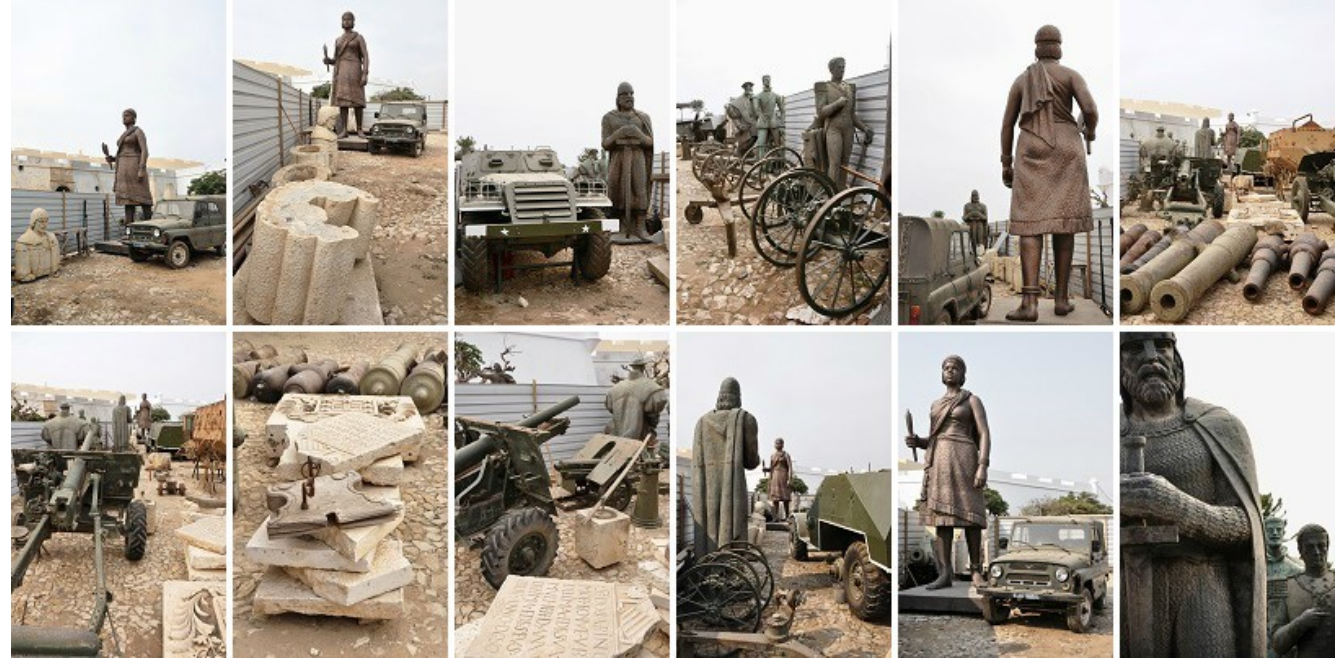

Figura 9 - Kiluanji Kia Henda. Série "Homem Novo". Balumuka (Ambush). 2010. Fonte: Johannes Hossfeld, 2016.

R. Inter. Interdisc. Art\&Sensorium, Curitiba, v.7, n.2, p. 052 - 066 Jul.- Dez. 2020 
Na primeira e na segunda fotografia da série, o busto de Diogo Dias de Novais, considerado o fundador português de Luanda (em 1576) e fundador da Fortaleza de São Miguel, aparece no chão, enquanto a escultura da rainha Njinga - presente em quase todas as imagens da série como se estivesse em posição de confronto com as demais esculturas - encontra-se no fundo, descalça, imponente e grandiosa, ao lado de uma, aparentemente, minúscula viatura russa. Na terceira fotografia, vê-se isolado, ao lado de uma viatura, Dom Afonso Henriques, cujo perfil também é enquadrado na última imagem da série, onde, ao fundo, estão Vasco da Gama e Camões. Na quarta imagem da parte superior, as esculturas aparecem ao lado de suportes para canhões, suscitando a imagem de figuras humanas afixadas em cadeiras de roda, enquanto lançam um olhar para fora do espaço em que se encontram encerradas. Como o próprio Kia Henda comentou durante conferência no museu Tate Modern (em Londres), "são como cidadãos aos quais os vistos expiraram e não sabem o que fazer com eles... tendo de retornar ao local de origem" (HENDA, 2010 apud PEREIRA, 2014, p. 66) ${ }^{6}$.

"Redefining The Power", de 2011, também é parte do projeto "Homem Novo" e se constitui em uma série de performances em que Henda convida outros artistas angolanos a ocuparem os espaços vazios dos pedestais, de onde, há mais de trinta anos, foram retiradas as esculturas portuguesas. Enquanto isso, Henda registra as performances, do mesmo ângulo de imagens de cartões-postais antigos da cidade. Em "Redefining The Power III" (Figura 10), por exemplo, vê-se a ocupação do antigo monumento dedicado a Pedro Alexandrino, no largo de mesmo nome.
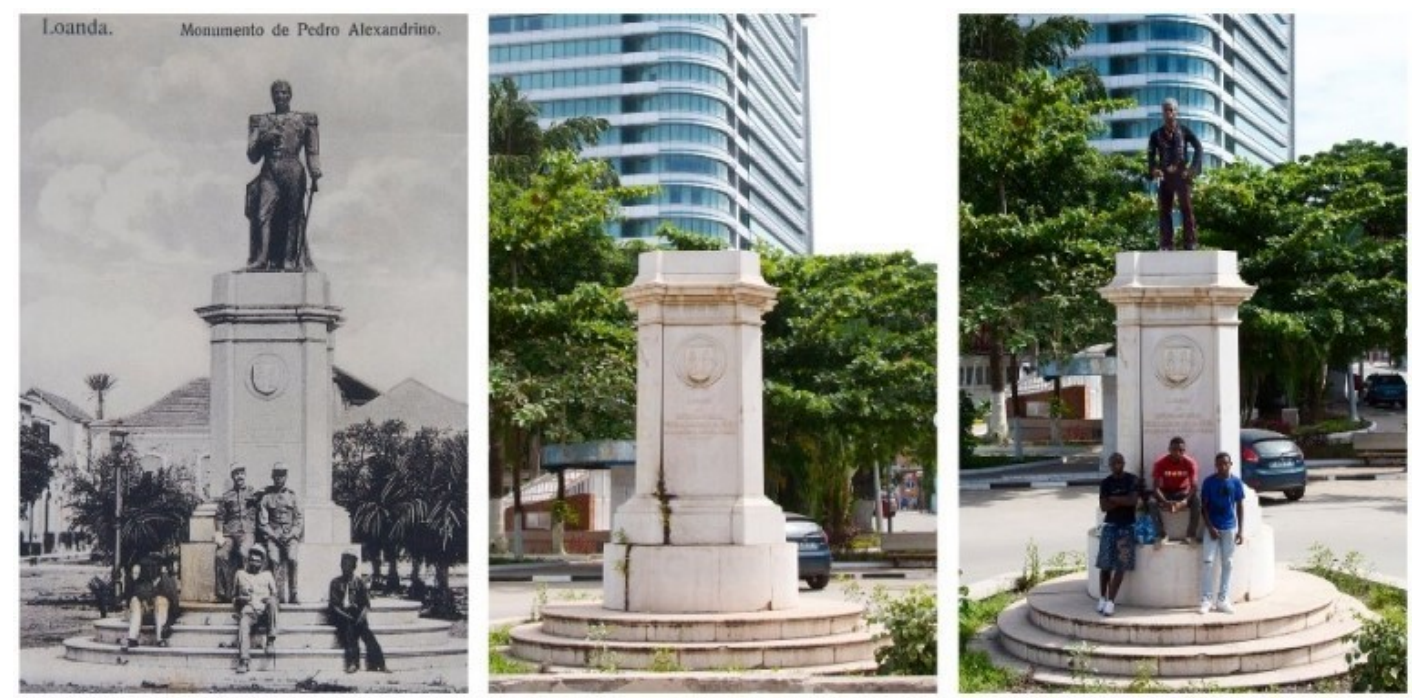

Figura 10 - Kiluanji Kia Henda. Série "Homem Novo". Redefining The Power III. 2011. 80 x 120 cm. Fonte: Johannes Hossfeld, 2016.

Justapondo três diferentes tempos, o arquivo fotográfico, na primeira posição, traz a imagem do Capitão de Mar e Guerra e Governador-geral de Angola do século XIX, com dois soldados portugueses ocupando a parte inferior do pedestal e três angolanos posicionados mais abaixo (que se pode ler como uma metáfora da hierarquia colonial). Na primeira fotografia feita por Henda (segunda

\footnotetext{
${ }^{6}$ Quando por ocasião de pesquisa de campo realizada em Luanda visitamos o Museu Nacional da História Militar, tal foi a surpresa ao nos depararmos com uma determinada disposição destas esculturas, que em muito lembra o enquadramento feito por Kiluanji Kia Henda em sua série fotográfica. Logo à entrada, avista-se a imponente rainha Njinga, como uma guardiã das muralhas externas. Atravessando o corredor principal que dá acesso aos ambientes do museu, encontra-se, no pátio interno, à direta, o busto de Agostinho Neto, que encara, a uma certa distância, Diogo Cão, Paulo Dias de Novais, Salvador Correia de Sá, Pedro Alexandrino da Cunha e Henrique de Carvalho. No fundo do mesmo pátio, encontram-se Don Afonso Henriques, Vasco da Gama e Camões.
} 
da série), o espaço do pedestal surge vazio e, ao fundo, no lugar do chão de terra e das antigas palmeiras, há uma calçada em cimento, a traseira de um carro (quase escondido pelo pedestal), árvores crescidas na parte mais externa da praça e um grande prédio que se estende para além do enquadramento da fotografia. Na última imagem, além de todos os elementos da fotografia anterior, Henda insere o "novo homem" angolano. No topo, quem substitui a figura de Pedro Alexandrino é o performer Miguel Prince: não mão esquerda, posicionada na cintura, ele tem um anel, enquanto na direita (ao contrário do Governador-geral português) segura uma espada; tem um colar pendurado ao pescoço, usa um turbante, calça, camisa boca de sino com detalhes coloridos, um cinto com uma coroa e um sapato preto. Substituindo os dois soldados portugueses, surgem, juntamente com uma sacola de plástico, três jovens que usam camisetas de algodão coloridas, bermuda, calça jeans e tênis.

\section{Considerações finais}

Teresa Isabel Matos Pereira (2014, p. 66), ao analisar a série "Balumuka (Ambush)", argumenta: "as imagens registadas por Kiluanji Kia Henda não deixam de aludir à situação paradigmática da arte pública, monumental, no que toca às suas funções de simbolização do poder político". E Maria José (2003, p. 4), ao comentar a estética de António Ole, afirma: “o lamento pelas zonas limite e pelos modos culturais e objectos perdidos, a reflexão em acto sobre os detritos e restos urbanos, nunca estão longe da jubilação de um saber fazer e saber fazer ver". É nesse sentido que Rosalyn Deutsche, no texto "A arte de ser testemunha na esfera pública dos tempos de guerra" (2009), argumenta acerca do papel que as artes devem desempenhar na expansão da democracia. A historiadora e crítica de arte, na esteira de Hannah Arendt, Emmanuel Lévinas e Jacques Rancière, considera que o artista que deseja aprofundar e estender a esfera pública tem uma dupla tarefa: criar trabalhos que ajudem aqueles que foram tornados invisíveis a fazerem sua aparição e desenvolver a capacidade do espectador para a vida pública, ao solicitar que responda a essa aparição. Quando António Ole e Kiluanji Kia Henda vasculham o passado a contrapelo, parecem estar respondendo às tarefas aventadas por Deutsche. Ao trazer para a esfera pública arquivos, objetos decaídos ou em risco de desaparecimento e esquecimento, os dois artistas angolanos reeducam a visão para a memória das vítimas do passado e do presente, para os invisíveis numa era de outros poderes estabelecidos.

António Ole, para além de vasculhar o passado de guerras do qual ele mesmo é testemunha direta, acusa a sua permanência no tempo presente, em consequência do não rompimento com estruturas políticas e socioeconômicas herdadas e atualizadas em outras formas de divisão e de abismos sociais. Por sua vez, Henda, que veio à luz numa Luanda independente, coloca em movimento as heterotopias do passado no presente do país. Os espaços outrora ocupados pelo colonizador, e agora vazios, são por ele transformados em monumentos vivos no lugar da pedra e dos metais frios das esculturas. De tal modo, as produções visuais destes artistas de diferentes vivências e gerações possibilitam ao espectador acompanhar heterotopias e heterocronias: seja de tempos coloniais ou de país independente (inserido na ordem econômica global/liberal); seja do efêmero ou do duradouro; enfim, do que não mais se vê, mas ainda continua presente, ainda que seja em forma de vestígios e ruínas. Ambos ativam e rasuram, via arte - em fotografias, instalações e performances - o arquivo, evidenciando o seu presente passado, o presente atual e o presente futuro, como argumenta Jacques Derrida em Mal de arquivo (2001). A própria desconstrução do conceito de arquivo na sua versão clássica, elaborada por esse filósofo francês, parece ecoar nas práticas artísticas de Ole e Kiluanji, ao romperem a formalidade do arquivo clássico e evidenciarem em suas incursões pela memória e história angolanas um poder (sobretudo colonial) que está permanentemente arquivando e destruindo o arquivo. Como resposta a essa prática destrutiva (pulsão de morte), os dois artistas realizam um duplo movimento: por um lado, desarquivam o passado, revisitando-o criticamente; por outro, fazem de suas produções um arquivo (estético, ético e político) contra o esquecimento, construindo uma memória ativa das lutas, das vítimas e dos rastros da violência colonial. 


\section{Referências}

ANGOLA. MINISTÉRIO DO PLANEJAMENTO. Relatório de Inquérito Integrado sobre o BemEstar da População. Luanda: Instituto Nacional de Estatística, 2011. (vol. II) Disponível em: $<$ www.info-angola.com/attachments/article/.../IBEP_Relatorio_de_Tabelas_Vol.II-2011>. Acesso em: 10 out. 2018.

ASSMANN, Aleida. Além dos arquivos. In: Espaços da recordação: formas e transformações da memória cultural. Tradução de Paulo Soethe. Campinas, SP: Editora da Unicamp, 2011. p. 411-436.

CARTAS PARA ANGOLA. Direção de Coraci Ruiz e Júlio Matos. Brasil: Laboratório Cisco. Disponível em: <https://www.laboratotiocisco.org/cartas>. Acesso em: 21 mar. 2016. (Documentário).

DERRIDA, Jacques. Mal de arquivo: uma interpretação freudiana. Tradução de Cláudia de Moraes Rego. Rio de Janeiro: Relume Dumurá, 2001.

DEUTSCHE, Rosalyn. A arte de ser testemunha na esfera pública dos tempos de Guerra. In: Revista Concinnitas, ano 10, vol. 2, 2009, p. 174-183.

DULLEY, Iracema. Fontes e contextos do Arquivo Nacional de Angola: entrevista com Alexandra Aparício. In: Revista do Arquivo Geral da Cidade do Rio de Janeiro, n.12, 2017, p.229-245. Disponível em: < http://wpro.rio.rj.gov.br/revistaagcrj/fontes-e-contextos-do-arquivo-nacional-deangola-entrevista-com-alexandra-aparicio/>. Acesso em: 14 abr. 2018.

FONSECA, $M^{\mathrm{a}}$ Nazareth Soares. Literaturas africanas de língua portuguesa: percursos da memória e outros trânsitos. Belo Horizonte: Veredas \& Cenários, 2008.

FOUCAULT, Michel. A heterotopia. In: O corpo utópico; as heterotopias. Tradução Salma Tannus Muchail. São Paulo: N-1 Edições, 2013. p. 19-30.

GUERRA, Sérgio. Duas ou três coisas que vi em Angola. Salvador: Maianga, 2000.

HOSSFELD, Johannes (ed.). Kiluanji Kia Henda: Travelling to the sun through the night/Viajando ao sol durante a noite. Göttingen: Steidl/Goethe Institut, 2016.

HUG, Alfons. António Ole e o novo objet trouvé em África. In: MACHADO, Rosário Sousa (ed). António Ole. Marcas de um Percurso (1970/2004) (Catálogo da exposição). Lisboa: Grupo Caixa Geral de Depósitos; Culturgest, 1998. p. 100-107.

INSTITUTO CAMÕES. António Ole e contiguidades (Catálogo da exposição). Luanda: Centro Cultural Português, 2003.

MACEDO, Tania. Luanda, cidade e literatura. São Paulo: Editora UNESP; Luanda: Nzila, 2008.

PEREIRA, Teresa Matos. A cidade visível e a cidade tangível: a paisagem urbana como palimpsesto na obra de António Ole. In: Revista Estúdio, vol.4, n.8, 2013, p.181-187. Disponível em: $<$ http://www.scielo.mec.pt/scielo.php?script=sci_abstract\&pid=S1647-

$61582013000200024 \& \operatorname{lng}=$ pt\&nrm=iso $>$. Acesso em: 10 out. 2018.

. Kiluanji Kia Henda: Ficção, Ironia, Desconstrução. In: Revista Estúdio, Artistas sobre

outras obras, v. 5 (9), 2014, p. 60-69. Disponível em: $<$ http://www.scielo.mec.pt/pdf/est/v5n9/v5n9a07.pdf >. Acesso em: 10 out. 2018.

REDE BANDEIRANTES DE COMUNICAÇÃO. Luanda - O mundo segundo os brasileiros. Disponível em: $<$ http://entretenimento.band.uol.com.br/omundosegundoosbrasileiros $>$. Acesso em: 12 abr. 2016.

RIBEIRO, Anabela Mota. Entrevista com Kiluanji Kia Henda, 2011. Disponível em: $<$ https://anabelamotaribeiro.pt/kiluanji-kia-henda-177444>. Acesso em: 12 nov. 2018. 
SALGADO, Sebastião. África. São Paulo: Taschen, 2007.

SARLO, Beatriz. Tempo passado: cultura da memória e guinada subjetiva. Tradução Rosa Freire d'Aguiar. São Paulo: Companhia das Letras; Belo Horizonte: UFMG, 2007.

SIEGERT, Nadine. Aesthetic Autopsy. Collective Memory and Trauma in Contemporary Art from Angola. In: Artl@s Bulletin, vol. 7, Issue 1, 2018, p. 52-64. Disponível em: $<$ https://docs.lib.purdue.edu/artlas/vol7/iss1/7/>. Acesso em: 22 set. 2018.

SITAK, Rufino Borges José; BUMBA, Pedro Fernandes; SANTANA, Yanara Dorado. Breve abordagem do papel dos museus públicos na preservação do patrimônio cultural: os museus públicos de Angola. In: Revista Publicando, v. 5, n. 16. (1). 2018, p. 265-286. Disponível em: $<$ https://www.rmlconsultores.com/revista/index.php/crv/article/download/.../pdf_1099>. Acesso em: 18 dez. 2018. 